\title{
Developing Sustainable Banana Production Systems: a Case Study from Tropical Australia
}

\author{
J. Bagshaw ${ }^{1}$ and S. Lindsay ${ }^{2}$ \\ Queensland Department of Primary Industries \& Fisheries \\ Indooroopilly $^{1}$ and South Johnstone ${ }^{2}$ \\ Queensland \\ Australia
}

Keywords: best management practice, economic tools, environment, environmental risk assessment, integrated farming systems

\begin{abstract}
The north Queensland banana industry is under pressure from government and community expectations to exhibit good environmental stewardship. The industry is situated on the high-rainfall north Queensland coast adjacent to two natural icons: the Great Barrier Reef to the east and World Heritage-listed rainforest areas to the west. The main environmental concern is agricultural industry pollutants harming the Great Barrier Reef. In addition to environmental issues the banana industry also suffers financial pressure from declining margins and production loss from tropical cyclones. As part of a broader government strategy to reduce land-based pollutants affecting the Great Barrier Reef, we facilitated formation of a pilot banana producers group to address these environmental and economic pressures. Using an integrated farming systems approach we worked collaboratively with these producers to conduct an environmental risk assessment of their businesses, and then to develop best management practices (BMP) to address environmental concerns. We also sought input from technical experts to provide increased rigour for the environmental risk assessment and BMP development. The producers' commercial experience ensured new ideas for improved sustainable practices were constantly assessed through their profit-driven 'filter' thus ensuring economic sustainability was also considered.

Relying heavily on the producers' knowledge and experience meant the agreed sustainable practices were practical, relevant and financially feasible for the average-sized banana business in the region. Expert input and review also ensured that practices were technically sound. The pilot group producers then implemented and adapted selected key practices on their farms. High priority practices addressed by the producers group included optimising nitrogen fertiliser management to reduce runoff water nitrification, developing practical ground cover management to reduce soil erosion and improving integrated pest management systems to reduce pesticide use.

To facilitate wider banana industry understanding and adoption of the BMP's developed by the pilot group, we conducted field days at the farms of the pilot group members. Information generated by the pilot group has had wider application to Australian horticulture, and the process has been subsequently used with the north Queensland sugar industry. Our experiences have shown that integrated farming systems methodologies are useful in addressing complex issues like environmental and economic sustainability. We have also found that individual horticulture businesses need on-going technical support for change to more sustainable practices. One-off interventions have little impact, as farm improvement is usually an on-going incremental process. A key lesson from this project has been the need to develop practical, farm scale economic tools to clarify and demonstrate the financial impact of alternative management practices. Demonstrating continued profitability is critical to encourage widespread industry adoption of environmentally sustainable practices.
\end{abstract}




\section{INTRODUCTION}

About $85 \%$ of Australia's banana industry is situated on the high-rainfall north Queensland coast adjacent to two natural icons: the Great Barrier Reef to the east and World Heritage-listed rainforest areas to the west. Increasing community and scientific concern about land-based pollutants affecting the health of the Great Barrier Reef has pressured the north Queensland banana industry to implement and exhibit good environmental practices. In 2003 the Queensland Government released the Reef Water Quality Protection Plan (Reefplan) to formalise the overall approach to address this issue (Queensland Government, 2003). The goal of the Reefplan was to halt and reverse the decline in water quality entering the Reef within 10 years. The plan listed nine strategies, including promotion of self-management approaches and education and extension aimed at increasing the voluntary uptake by producers of sustainable practices.

Participatory processes are widely regarded as providing the best approach to improving sustainability in agriculture (Allen et al., 1995; Marsh, 1998; Van de Fliert, 2003). Pannell et al. (2006) also highlight the differences in motivations and circumstances between individual farmers, and the need to be cognisant of these in influencing voluntary change. Our aim was to test a highly participative environmental risk assessment process that allowed for individual differences.

In addition to the banana industry having to address environmental issues, it also faces financial pressure from declining margins and recently suffered complete crop and plantation loss from a tropical cyclone. These issues had to be integrated into our group processes to take full account of drivers and barriers to farm practice change. Pannell et al. (2006) suggest that while economics is a very important driver when making decisions about sustainable practices, it is not the sole consideration for most farmers. Personal, social and biophysical issues are also important. However, when economic stress is high, these other issues decline in importance.

\section{METHODS}

In December 2000 a small group of banana producers from the Innisfail district in coastal north Queensland began meeting formally as the Better Banana Businesses Sustainability (BBBS) group. The agreed role of the group was to discuss a raft of issues affecting the sustainability of small, family-operated farms, by sharing ideas and information and discussing options for addressing these issues. The genesis of this group started with individual banana producers talking with local government extension staff, expressing concern at the capacity of their businesses to meet future challenges. These challenges included reduced profitability, changing market conditions and environmental requirements. Local extension staff assisted eight of these producers to form the BBBS group. The group initially pursued several small projects in new market development, then in 2003, having developed into a well established and cohesive group, they decided to focus on environmental issues. At this time various government and research organisations started presenting evidence that land-sourced pollutants were damaging the Great Barrier Reef, and particularly emphasised diffuse sources of sediment, nutrients and pesticides from coastal farming adjacent to the Reef. The banana producers in the BBBS group, along with the whole banana industry, felt this scrutiny keenly and wanted to demonstrate their environmental stewardship. Their main concern was that community scrutiny may result in costly regulation or restrictions to conducting their business, further adding to their cost of production and eroding profits, or even restricting their right to farm. As a result they recognised the need to practice and demonstrate sustainable production methods.

After scoping available environmental management systems, the BBBS group decided that none of these systems was appropriate to their needs as small business operators, or were not tailor-made to their banana growing operations. We therefore proposed an environmental risk assessment process. The process aimed to examine all aspects of their businesses that could potentially impact the environment, along with aspects that enhanced environmental values on, near and downstream from their farms. 
We planned the process to be strongly consultative whereby we acted as facilitators and subject matter input was mainly provided by the producers.

The risk assessment process used was to:

- Identify and chart all farming processes from site selection through to packing.

- For each process, identify potential impacts on the environment, taking into account land and soil, air and water quality, biodiversity and energy efficiency.

- Identify farm activities that enhance environmental value on-farm.

- Arrange potential impacts according to environmental issue impacted.

- Prioritise issues and activities.

- For each high priority activity, explore ways to reduce or minimise potential impacts.

- Explore ways to further enhance on-farm environmental value.

This process was conducted over a six-month period, with two-hour meetings twice a month. The meetings were scheduled at times when the producers were less busy on their farms, usually late afternoon or evening.

The producers provided most of the ideas and information through the process, but to ensure technical rigour, we included specialist knowledge in various ways. For example, we invited specialists in agronomy and natural resource management to join discussions when producers admitted limited knowledge about some issues, or we challenged the producers about some of their thinking, or we injected new ideas for discussion when it became obvious the group were not aware of the latest research or technology about an issue. In all cases, the producers had final say about what they felt was feasible, or wanted to research further. We also presented relevant information generated by the group to specialists for their review and critical analysis. Specialists included staff from regional community-led natural resource management groups, government departments with roles in primary industries and natural resource management and government-funded statutory organisations such as the Great Barrier Reef Marine Park Authority.

Following identification of sustainable practices, the members of the BBBS group were asked to develop their own individual action plan for their farms, based on the priority issues identified during the risk assessment. The action planning process encouraged the producers to link practice improvements to environmental objectives, and to include environmental monitoring to evaluate progress.

After about six months, we organised visits by the BBBS group to member farms to see progress in action, and to share and discuss practical considerations about the practices being improved, implemented or trialled.

Where improved practices were well established and working, we then facilitated field days on these farms for the wider banana industry. A feature of these field days was that the producers were 'up front' presenting the information.

\section{RESULTS}

\section{Best Management Practices}

The high priority environmental issues identified by the group were farm-based pollutants entering the Great Barrier Reef lagoon via waterways. The main concerns were nutrients, sediment and chemicals. Three key practices were identified by the group after specialist review to address these issues.

1. Optimising Fertiliser Management to Reduce Runoff Water Nutrification. Previous research identified losses of nitrogen and phosphorus from banana production systems (Prove et al., 1996). Phosphorus was lost in the movement of sediment off paddocks, while nitrogen was lost mostly as leaching of nitrates beyond the plant's effective root zone. In response to these findings the Queensland banana industry funded research in 1996 to investigate ways of increasing the efficiency of nitrogen and pottasium fertiliser use while maintaining productivity. This research identified the opportunity to reduce inputs of these nutrients by $30 \%$ to $50 \%$ without reducing yield or quality, and suggested some strategies to improve fertiliser use efficiency. Strategies 
included matching fertiliser inputs to rate of plant growth, applying fertiliser in small amounts at regular intervals as fertigation, maximising crop uptake of nutrients, monitoring soil and leaf nutrient levels and placing crop trash on plant rows to maximise recycling of nutrients by the crop (Daniells and Armour, 2003). This meant that crop growth rate and nitrate levels needed to be monitored and nitrate contributed by crop trash accounted for. Also the BBBS group identified that by adding organic matter and maintaining soils at neutral $\mathrm{pH}$, the ability of soils to hold nutrients was improved.

2. Developing Practical Ground Cover Management to Reduce Soil Erosion. The BBBS group identified that retaining soil cover as much as possible was the key to reduced soil erosion. To achieve this the group identified the following practice options:

- Maintain grassed inter rows and slash or mow grass as required.

- Place all banana trash into the plant rows to provide mulch for ground cover.

- Maintain grass on headlands/roads where possible, or stabilise bare headlands with rock or gravel.

- Prepare for planting using minimum tillage (use herbicide to kill ground cover only on the plant row area, then use two or three cultivations to prepare this area. Maintain grass on the inter-row area).

- Stem-inject the old crop with herbicide, allow to die and decompose in situ and leave grass cover intact. Renovate planting beds just before re-planting.

- Maintain ground cover during the fallow period between crops, particularly during the wet season. Cover may be either a planted non-nematode host cover crop or volunteer grass.

- Design farm layout for good runoff and drainage. Form and maintain broad, shallow grassed drains.

3. Improving Integrated Pest Management Systems to Reduce Pesticide Use. In 2003 established IPM systems already existed for bunch pests and leaf diseases, including monitoring systems, action thresholds and targeted application methods with narrowspectrum pesticides to minimise 'landscape' and off-target application. The BBBS group specifically targeted practices for an integrated nematode management system for the burrowing nematode (Radophilis similis). The key elements of this integrated nematode management system were to effectively destroy the infested crop, plant nematoderesistant fallow crops, use planting material free of the pest and use nematicides strategically based on monitoring. Group members recognised that some of the practices not only reduced nematicide use but also potentially reduced sediment and pesticide transports in runoff water by reducing the number of pesticide applications required and providing ground cover during fallow periods. The group members used this opportunity to integrate the IPM system for burrowing nematodes with the reduced-tillage fallowing and planting system.

\section{Adoption of Sustainable Practices by the BBBS Group Members}

When developing action plans, the eight members of the BBBS group were able to identify gaps in their own practices (when measured against the 'best practice' list the group had generated) and set plans to implement or improve their practices, or to trial some of the newer practices that emerged in discussions between the group and technical specialists.

Evaluation of the group identified the following outcomes:

- Increased confidence in their ability to meet external pressures to improve their environmental performance.

- Broadened awareness of environmental issues and the impacts of their businesses on the environment.

- Greater willingness to interact with the community and regulators about environmental issues. Initially group members were suspicious of the organisations that regulate environmental matters; however by the end of the process, the pilot group members indicated they would like to invite staff from key environmental organisations to their farms to showcase their environmental stewardship. 
- All the group members had identified practices for improvement or implementation, and implemented key practices identified in their action plans. These included practice change to better manage nutrients, soil erosion and soil health. One of the group members now has the externally certified Freshcare Environmental Code of Practice in place (Freshcare Ltd, 2006).

\section{Wider Use of the Best Management Practice (BMP) Information}

A banana industry representative group comprising three key industry leaders adapted the pilot group BMP's into industry-wide BMP's addressing water quality impacts for a floodplain landscape. This process in turn contributed to development of a catchment-based Water Quality Improvement Plan for bananas designed to mitigate landbased pollutants affecting the Great Barrier Reef.

Information that came out of the pilot group has subsequently contributed to development of the national Guidelines for Environmental Assurance in Australian Horticulture (Anon, 2006).

The participatory process used with the banana pilot group has been adapted and used by the 80,000 ha irrigated sugarcane industry in the Burdekin river catchment to develop agreed industry BMP's for water quality improvement.

\section{DISCUSSION}

\section{Group Formation and Effectiveness}

The use of farmer groups to facilitate change, rather than working with individuals, is strongly encouraged by extension agencies as the most efficient use of support resources. Cohesiveness of groups is a major determinant of how effectively change is facilitated in this way. We had facilitated the formation and functioning of the pilot group for two years before they decided to embark on the environmental risk assessment process. It is unlikely such a rigorous environmental risk assessment process would have been possible with a new group. Identifying and working with existing natural, functional groups will enable more effective and lasting outcomes. The alternative is to start with a new group as we did to address a priority of their choosing, before turning to sustainable practices if it is not an initial priority for them.

\section{Using the Participative Process}

Our process was highly participative. We guided the process, with little input into content. We valued the producers' knowledge and experience, listened to them, recorded and documented their input and fed it back to them for their review and approval. They had final say on the practices that made up the list of good environmental practices. New ideas and technologies introduced by specialists were often presented in response to a request from group members, and were discussed in a collaborative way. The environmental risk assessment process was presented and conducted as a group of equal partners (producers, specialists and facilitators) contributing their equally valid ideas and knowledge. Conducting the process in this very participative way was more time consuming, but it gave participants a sense of ownership, took advantage of local knowledge and experience, and provided a richness and diversity of ideas and issues that were relevant and practical to the producers. This resulted in a greater willingness by the grower participants to trial the practices on-farm as their shared experiences made them more confident of the management implications and practicalities of changing or modifying their practices. New ideas and practices from specialists were assessed for how they would fit the producers' existing farming systems and the process built a supporting environment between producers in which to trial practices and concepts.

\section{Adoption of Sustainable Practices}

The BBBS group members were already doing many of the identified sustainable practices. The object of encouraging them to develop action plans was about recognising 
what they were already doing well, and improving, implementing or trialling practices they were not doing so well. Monitoring of environmental condition was not well adopted for many reasons: it was not a business priority and was time-consuming; environmental changes can take a long time to show; impacts are often distant from the farm; and monitoring skills and equipment was limiting. Some simple tools such as erosion pegs for measuring erosion on farm, and turbidity tubes for measuring quality of runoff water were offered for grower use but not used. We did take some measurements on behalf of the producers to demonstrate the impact of their changed practices, and this gave visual encouragement for the group members to continue sustainable improvements. Most group members did monitor nutrient status of soil and plants, and gross erosion, because these influenced business profitability or were already current business practice.

\section{Integrated Farming Systems}

The BBBS group considered all aspects of their farming operations and likely impacts on the environment during the environmental risk assessment. It soon became obvious that it was difficult to separate out each component of their farming practices. There was a lot of interaction between practices and they needed to be viewed in an integrated way to achieve truly sustainable operations. For example, practice changes that helped reduce sediment movement could also be modified to incorporate aspects of an IPM system to manage burrowing nematode, and reduce some of the costs associated with land preparation and planting. Our integrated farming system approach allowed the group members to develop trial practices that addressed each issue.

\section{Need for On-Going Technical Support}

Each grower had different environmental issues on their farm, different practices and processes to improve or implement, different financial and social resources and different business or personal priorities that influenced what they decided to include in their environmental improvement plans. Hence at some point they needed individual technical support. Their implementation of new practices or change to improved practices tended to be incremental over time, as they trialled and assessed the practice according to their time and resources. They valued on-going technical support through all the stages of their continuous improvement process. For this reason one-off interventions had little impact.

\section{The Role of Economics in Sustainable Production}

Marsh (1998) points out that for innovations to be readily adopted, they must demonstrate a need (or respond to an expressed need), demonstrate an observable difference on-farm, especially for practices that have slow and indirect effects, and demonstrate a measurable benefit (in line with individual objectives). Further, Barr and Cary (2000) suggest that environmental innovation that has been profitable, or believed to be profitable by the farmer, is usually readily adopted on Australian farms. The challenge is to identify those innovations (practices) and demonstrate that they are potentially profitable as well as provide environmental benefits.

In the BBBS group, the producers' commercial experience ensured ideas for improved sustainable practices were constantly assessed through their profit-driven 'filter' thus ensuring economic sustainability was always considered. When trying to encourage adoption of these sustainable practices to those not involved in the BBBS group, it soon became apparent we needed to demonstrate the economic impacts to help producers with their decision making. However, we were unable to conduct any economic analysis due to lack of resources.

Discussions with BBBS group members indicated that a major driver of farm practice change was the potential to reduce farm input costs without productivity loss, either by reducing inputs or lowering unit costs. This was particularly important for fertilisers and pesticides where research data existed that showed reductions were practically feasible. 
Another important consideration by producers was efficiency in labour inputs and increased flexibility and timeliness from new practices. For example the minimum-tillage system saved some input costs (labour and fuel), but also reduced the time required for land preparation. Reduced land preparation time gave the producer more flexibility to work around adverse weather conditions, and increased the time available for other more strategic management roles. This advantage is best described as a reduced opportunity cost. Many of the changes implemented by BBBS group members offered both reduced cash and opportunity costs, and as a result were implemented quickly. Our experience from this project suggests that practice changes that do not provide reduced input costs but do reduce opportunity costs in management time are likely to be favourably received.

The implication from this is that practices need to be comprehensively assessed for all potential costs and benefits, both cash and non-cash, not just impacts on input costs or productivity. This assessment is probably best achieved by the development of interactive economic software 'tools' that allows producers to examine different financial scenarios to help them with decision making.

Thorough economic analysis of practice changes in selected case study farms would have provided clarity for producers, and perhaps contributed to increased uptake of sustainable practices. Good economic data would also help to justify use of public money (in the form of incentives) to encourage farmers to progress toward more sustainable practices that ultimately provide a public good.

\section{ACKNOWLEDGEMENTS}

This project was funded by the Queensland Department of Primary Industries \& Fisheries (DPI\&F) Improved Regional Service Delivery program. Thanks to the producer members of the BBBS group, and to staff of DPI\&F and Queensland Department of Natural Resources \& Water for their technical review.

\section{Literature Cited}

Anon. 2006. Guidelines for Environmental Assurance in Australian Horticulture. Lovell, J. (Ed). Horticulture Australia Ltd, Sydney, Australia.

Allen, W.J., Bosch, O.J.H. and Gibson, R.G. 1995. Farmers and scientists working together to achieve more sustainable land management.

http://www.landcareresearch.co.nz/research/sustainablesoc/social/afres.asp.

Barr, N. and Cary, J. 2000. Influencing improved natural resource management on farms: a guide to understanding factors influencing the adoption of sustainable resource practices. Bureau of Rural Sciences, Department of Agriculture, Fisheries and Forestry, Canberra, Australia.

Daniells, J. and Armour, J. 2003. Managing crop nutrition in banana production. Queensland Department of Primary Industries \& Fisheries, Information Series QI 03029, South Johnstone, Australia.

Freshcare Ltd. 2006. Freshcare Environmental Code of Practice. Freshcare Ltd, Sydney, Australia.

Marsh, S.P. 1998. What can agricultural researchers do to encourage the adoption of sustainable farming systems? http://www.general.uwa.edu.au/dpanell/dpap987f.

Pannell, D.J., Marshall, G.R., Barr, N., Curtis, A., Vanclay, F. and Wilkinson, R. 2006. Understanding and promoting adoption of conservation technologies by rural landholders. Aust. J. Exp. Ag. 46:1407-1424.

Prove, B.G., Moody, P. and Reghenzani, J.R. 1996. Nutrient balances and transport from agricultural and rainforest lands: a case study in the Johnstone River catchment. Project Final report DAQ3S. Land and Water Resources Research and Development Corporation, Canberra, Australia.

Queensland Government. 2003. Reef Water Quality Protection Plan. www.reefplan.qld.gov.au.

Van de Fliert, E. 2003. Recognising a climate for sustainability: extension beyond transfer of technology. Australian Journal of Experimental Agriculture 43:29-36. 
